\title{
Thermo-Mechanical and Isothermal Low-Cycle Fatigue Behavior of 316L Stainless Steel in High-Temperature Water and Air
}

\section{Hans J. Leber, Stefan Ritter* and Hans-Peter Seifert}

Paul Scherrer Institut (PSI), Nuclear Energy and Safety Research Dep., Lab for Nuclear Materials, 5232 Villigen PSI, Switzerland

\section{ABSTRACT}

Two unique facilities for isothermal low-cycle fatigue (LCF) and in-phase (IP) or out-ofphase (OP) thermo-mechanical fatigue (TMF) testing of tubular specimens under boiling water reactor (BWR) and pressurized water reactor (PWR) coolant conditions were set up and successfully tested. The systems allow both strain- and stress-controlled fatigue experiments with very small strain amplitudes or complex stress/strain profiles with superimposed rather rapid temperature changes $\left(100-340^{\circ} \mathrm{C}\right)$ under flowing conditions. The present article introduces the new test facility and briefly discusses the first results of these experiments.

In contrast to air, a strong effect of temperature on LCF and TMF lives was observed in de-oxygenated and hydrogenated high-temperature water environment, where both lives decrease with increasing temperature above $100{ }^{\circ} \mathrm{C}$. The TMF life is between that of the isothermal LCF tests at minimum and maximum temperature. The IP TMF life is shorter than that of OP TMF and close to the LCF life at maximum temperature. The OP TMF life is close to that of LCF at minimum temperature. In hydrogenated environment, the LCF and TMF lives seem to be slightly shorter than predicted by the NUREG/CR-6909 approach of the US NRC Reg. Guide 1.207. Significant environmental effects were observed at $100{ }^{\circ} \mathrm{C}$, which is significantly below the temperature threshold of $150{ }^{\circ} \mathrm{C}$.

KEY WORDS: Corrosion fatigue, high-temperature water, thermo-mechanical fatigue, stainless steel, low-cycle fatigue, BWR.

\footnotetext{
* Corresponding author, e-mail: stefan.ritter@psi.ch
}

This document is the accepted manuscript version of the following article:

Leber, H. J., Ritter, S., \& Seifert, H. P. (2013). Thermo-mechanical and isothermal low-cycle fatigue behavior of type 3161 stainless steel in high-temperature water and air. Corrosion, 69(10), 1012-1023. https://doi.org/10.5006/0875 


\section{INTRODUCTION}

Time to crack initiation of austenitic stainless steels in light water reactor (LWR) environments may be significantly shorter than in air, if certain conjoint threshold conditions with regard to temperature, strain rate and strain amplitude were simultaneously satisfied. ${ }^{1-6}$ Based on laboratory investigations, different proposals ${ }^{7-9}$ were established for incorporating environmental effects into the fatigue design procedure according to Section III of the American Society of Mechanical Engineers (ASME) boiler and pressure vessel (BPV) code or even implemented in certain national codes (e.g., in Japan). The practical application of these procedures is complex and also related to some uncertainties. ${ }^{3,6}$ Furthermore, there are relevant differences between fatigue design, lab tests and component conditions in the field (e.g., thermo-mechanical fatigue (TMF), mean stress, static load hold times, small strain amplitudes, combined high- and low-cycle fatigue (HCF/LCF) loading, multi-axiality, variable amplitude, etc.). ${ }^{3,6}$ The suggested procedures have thus not (yet) found full acceptance by the industry, and further experiments under more realistic and plant-relevant conditions are required.

For a balanced assessment of possible effects of the environment on the fatigue crack initiation in the field, the stress and strain conditions have to be adapted better to the real conditions (TMF, small strain amplitudes, mean stresses, hold times under constant loads, spectrum loading with variable amplitude, multi-axiality). At the same time the surface condition and the residual stress state have to be considered at small strain amplitudes and in the transition field to HCF. For this reason, a new facility was constructed at PSI to investigate some of these unexplored aspects.

The main aim of this work was to design a new, unique and flexible test facility with the ability to study TMF initiation and mean stress or load sequence/history effects on isothermal LCF/HCF initiation at small strain/stress amplitudes in LWR environments. For this purpose, two existing facilities for TMF tests in air with tubular specimens, induction heating and air 
cooling, which were constructed in the framework of a $\mathrm{PhD}$ thesis ${ }^{10}$, were significantly modified and adjusted for high-temperature water tests, and connected to high-temperature water loops. Furthermore, this thesis also provided the reference TMF and isothermal LCF behavior in air in the temperature range from 100 and $340{ }^{\circ} \mathrm{C}^{10-12}$ and also involved detailed microstructural investigations, which thus both will allow direct comparisons and conclusions towards the cracking mechanism in air and high-temperature water.

After the initial construction of the new facilities, many pre-tests were necessary to optimize the heating and cooling device as well as the specimen loading grips and sealing until reproducible in-phase (IP) and out-of-phase (OP) TMF tests could be performed. In a second step, the new facility was qualified by a set of TMF and isothermal LCF tests in de-oxygenated high-temperature water. After this successful qualification phase, the TMF and isothermal LCF behavior was studied in boiling water reactor (BWR)/hydrogen water chemistry (HWC) environment at different strain amplitudes and strain rates between 100 and $288^{\circ} \mathrm{C}$. The present article introduces the new test facility and briefly discusses the first results of these tests.

\section{MATERIALS AND EXPERIMENTAL PROCEDURE}

\section{Materials and specimens}

The investigated material was taken from a non-stabilized AISI 316L (UNS S31603) austenitic stainless steel pipe with an outer diameter of $219 \mathrm{~mm}$ and a wall thickness of $23 \mathrm{~mm}$. The seamless pipe was manufactured and processed according to the requirements of the ASME BPV Code. The processing sequences of the seamless pipe material consisted of hot working,

solution annealing, water quenching to room temperature, pickling and grinding. The chemical composition and mechanical tensile test properties of the pipe material in the as-received 
condition are given in Tables 1 and 2. The material had an average grain size of $35 \mu \mathrm{m}$, corresponding to ASTM grain size number 7. For the tests in air, the specimens were subjected to a special solution annealing heat treatment $\left(1050{ }^{\circ} \mathrm{C} / 1 \mathrm{~h} /\right.$ vacuum; furnace cooling to $950{ }^{\circ} \mathrm{C}$ in vacuum; quenching in argon to room temperature) after manufacture to reduce the residual stresses $^{10-12}$. However, for the tests in high-temperature water, the specimens were in the same as-received condition like the original pipe pieces. No difference in microstructure was observed for both cases, but an effect of the modified heat-treatment at very small strain amplitudes in the transition region to HCF cannot be fully excluded.

For the TMF and isothermal LCF tests in high-temperature water tubular specimens with a wall thickness of $2.5 \mathrm{~mm}$ and an outer diameter of $10 \mathrm{~mm}$ in the gauge section were used (Figure 1). The specimens were fabricated according ASTM E606 in the axial direction of the pipe (L orientation) and the inner surface was honed to an average surface roughness of $0.2 \mu \mathrm{m}$. The specimens were heated and cooled by the pressurized high-temperature water. The fixed pressure of 200 bar resulted in a circumferential hoop stress on the inner surface of $33 \mathrm{MPa}$, which is a factor of 5 lower than the axial stress amplitudes in the TMF and LCF tests. The wall thickness was larger than in the tests in air $(1.25 \mathrm{~mm})$ to reduce the probability for leakage at the end of test criteria (5\% maximum stress drop fatigue initiation criteria). The inlet and outlet nozzles were electron beam welded to the specimen heads. Two additional nozzles and short dead end pipe sections were welded for symmetry reasons to avoid asymmetrical heating and straining (Figure 1). The specimens were not electrically insolated from the loading grips. 


\section{Test facilities and experimental procedure}

Figures 2 and 3 show a schematic and pictures of the TMF test facilities. The tubular specimens were fixed in a special water-cooled load frame in an electromechanical LCF testing system (Instron 8862, $100 \mathrm{kN}$ ) and connected to a sophisticated high-temperature water loop, which allows the simulation of BWR and pressurized water reactor (PWR) water chemistry conditions. The cooling and heating of the specimens was done by the pressurized water, which was circulating through the specimen. The temperature of the water was controlled by induction heating of a tubular section before the inlet of the tubular specimen (and a heat exchanger and cooling station), which allowed heating and cooling rates of up to $4{ }^{\circ} \mathrm{C} / \mathrm{s}$. Since the induction heating system is in some distance from the specimen, the flow rate controls heating and cooling rate of the specimen. Any too large variation of the flow rate would affect the synchronization between the applied temperature and mechanical profile. The TMF system allows strain- and stress-controlled tests with complex shapes, but in the first test matrix a fully reversed triangular

mechanical strain profile $\left(\mathrm{R}_{\varepsilon}=-1, \varepsilon_{\max }=\left|\varepsilon_{\min }\right|\right)$ was applied (the authors are aware that the applied temperature and fully reversed mechanical strain profiles do not necessarily correspond to exact loading conditions occurring in nuclear power plant components). The strain was measured on the outer diameter of the gauge section by a TMF extensometer. The temperature of the specimen is monitored by a ribbon type thermocouple at the outer surface of the specimen. During the test, all important mechanical and thermal parameters like mechanical, thermal and total strain, load, stress, displacement and temperature are continuously recorded, as well as their extreme and range values for each cycle. The cyclic plastic behavior over the whole fatigue lifetime is thus fully documented. Similarly, the environmental parameters like dissolved oxygen (DO) and hydrogen (DH), electrical conductivity $\kappa, \mathrm{pH}$, temperature, pressure and flow are also continuously recorded.

Because of the excellent heat transfer between the water and inner surface and the high 
thermal conductivity and small wall thickness of the stainless steel specimen, there was only a very small temperature difference between the water and specimen. The through-wall and axial temperature gradients were also minimal under typical test conditions. This was confirmed in several pre-tests with specimens, which were instrumented with multiple thermocouples. The TMF tests were performed according to the current code of practice and ASTM E2368 and ISO 12111 standards. ${ }^{13-15}$ Before the beginning of the test series, different deviations and tolerances such as temperature variation between the target and effective specimen temperature, axial and radial temperature deviation, both within the gauge length, were checked and minimized so that they fit as well as possible into the tolerance field defined by the code of practice and the mentioned standards. The same procedure was applied to the maximum thermal strain hysteresis, the maximum stress during the zero stress test (verification step) and the phase shift between temperature and mechanical strain profile.

Before starting a TMF or isothermal LCF test, the specimens were pre-oxidized in the test environment at the maximum (for TMF) or test (LCF) temperature for $60 \mathrm{~h}$ at a controlled constant stress level of $20 \mathrm{MPa}$. The TMF and isothermal LCF tests were performed in highpurity, neutral de-oxygenated (nitrogen purging) or hydrogenated (150 ppb DH) water in the temperature range from 100 to $340{ }^{\circ} \mathrm{C}$ or 100 to $288{ }^{\circ} \mathrm{C}$, respectively. The conductivity in the inlet and outlet water was 0.055 and $\leq 0.07 \mu \mathrm{S} / \mathrm{cm}$, respectively. The $\mathrm{pH}$ at temperature varied from 6.1 at $100{ }^{\circ} \mathrm{C}$ to 5.6 around $250{ }^{\circ} \mathrm{C}$ and 6.0 at $340{ }^{\circ} \mathrm{C}$. The electrochemical corrosion potential (ECP) and redox potential were not measured. In the hydrogenated water the redox potential of the environment (and ECP of the specimens in isothermal LCF tests) is expected to vary from $-390 \mathrm{mV}_{\mathrm{SHE}}$ at $100{ }^{\circ} \mathrm{C}$ and $-570 \mathrm{mV}$ SHE at $340{ }^{\circ} \mathrm{C}^{1-3}$. In de-oxygenated water slightly higher values of -310 and $-440 \mathrm{mV}$ SHE are expected. Because of pre-oxidation at the maximum temperature, the ECP values in TMF tests are expected to be close to the redox potential at maximum temperature. The flow rate of the water at room temperature was $30 \mathrm{l} / \mathrm{h}$, which 
corresponds to a turbulent flow with an average flow rate within the tubular specimen of 0.4 and $0.7 \mathrm{~m} / \mathrm{s}$ at 100 and $340{ }^{\circ} \mathrm{C}$, respectively.

After the pre-oxidation period, in agreement with standard TMF practice, the following four step procedure was applied in case of TMF tests, which is shown in Figure 4 and discussed in ${ }^{12}$ : In the stabilization phase several cycles of temperature profile were applied under zero load control. After stable and homogenous thermal conditions were reached, the thermal strain (hysteresis) corresponding to the thermal expansion and contraction of the specimen was measured under zero load control. In the subsequent verification phase, in addition to the temperature profile the captured thermal strain profile was actively applied in strain-control and the resulting stress (which should be zero) measured. Finally, in the TMF testing phase, the fully reversed triangular mechanical strain profile $\left(\mathrm{R}_{\varepsilon}=-1, \varepsilon_{\max }=\left|\varepsilon_{\min }\right|\right)$ was additionally superimposed to the thermal strain profile. Therefore, the stress response is due to the mechanical strain only.

In the test the stress-strain behavior was continuously measured over the whole fatigue lifetime. The end of test and fatigue initiation was usually defined by the point at which the maximum stress $\sigma_{\max }$ decreases $5 \%$ below a tangent line, drawn at the last point of zero curvature on the curve of $\sigma_{\max }$ versus cycle number in linear scaling. This stress drop very roughly corresponds to a reduction of the specimen cross section by the cracks of $5 \%$. In most cases this did not lead to a leakage of the tubular specimens. In case of leakage by cracking, this defined the end of test and the experiment was automatically shut-down in such a case. Leakage occurred in 10 to $20 \%$ of the tests, mainly in cases where crack initiation occurred outside the gauge and strain measurement section, but not exclusively. Crack initiation always occurred on the inner, water-touched surface, in contrast to corresponding tests in air.

With the installed system, IP and OP TMF experiments between 100 and $340{ }^{\circ} \mathrm{C}$ can now be performed with a triangular temperature profile with a minimum cycle period of $120 \mathrm{~s}$ with 
minimal axial and through-wall temperature gradients fulfilling the requirements of international standards for TMF experiments. Typical examples for the course of temperature and strain during a cycle in IP and OP TMF tests in high-temperature water are shown in Figure 5. The system thus now allows both strain- and stress-controlled fatigue experiments with very small strain amplitudes with superimposed rather rapid temperature changes under turbulent flowing conditions, which are some of the major advantages with regard to autoclave tests under quasi-stagnant conditions. In the latter case, precise strain measurements at small strain amplitudes are very challenging and only very slow temperature changes can be applied.

\section{RESULTS AND DISCUSSION}

\section{Crack initiation and short crack growth in TMF and LCF tests in air}

The IP and OP TMF and isothermal LCF behavior between 100 and $340{ }^{\circ} \mathrm{C}$ with a triangular waveform at three different total strain amplitudes of $0.5,0.4$ and $0.3 \%$ was

investigated in a previous study ${ }^{10-12}$ and is thus not further discussed here. Besides the cyclic plastic behavior, the evolution of surface topography and microstructure during TMF experiments was characterized by atomic force, light, scanning and transmission electron microscopy. The temperature dependence of yield stress, which decreases with increasing temperature resulted in the development of different peak stresses and non-zero compressive (IP) and tensile (OP) mean stresses (typically 30 to $40 \mathrm{MPa}$ ) in TMF. In the investigated ranges of temperature and strain amplitude, respectively, IP TMF usually resulted in slightly longer life times than OP TMF. The lower fatigue life of OP TMF could be attributed to the development of a tensile mean stress and higher stress level leading to earlier crack initiation 
and a faster propagation. The increasing secondary hardening at small strain amplitudes at high temperature above $250^{\circ} \mathrm{C}$ by dynamic strain ageing may also result in a different fatigue lifetime between IP and OP TMF. ${ }^{10}$

\section{Crack initiation in TMF and isothermal LCF tests in high-temperature water}

TMF and isothermal LCF lives in de-oxygenated high-temperature water and air

The primary goal of this first test matrix of isothermal LCF and TMF in high-purity, deoxygenated high-temperature water at a relatively high mechanical strain amplitude $\Delta \varepsilon_{\text {mech }} / 2$ of $0.5 \%$ was, on the one hand, the validation of the developed test technique and, on the other hand, to evaluate the effect of the high-temperature water environment on time to fatigue initiation by direct comparison with corresponding tests in air. There were some minor differences in specimen geometry, fabrication, surface conditions and heat-treatment between the tests in air (which were optimized for the nano-scale investigations in ${ }^{10}$ ) and the experiments in high-temperature water. It is expected that those differences did not significantly affect the fatigue life of the tested stainless steel at this large strain amplitude. Furthermore, the strain rate in the air tests $(0.061 \% / \mathrm{s})$ was slightly faster than in the high-temperature water experiments $(0.0167 \% / \mathrm{s})$, but such a small strain rate change does not affect the lifetime until fatigue initiation in air remarkably.

Figure 6 exemplarily compares the environmental reduction of fatigue lives in IP and OP TMF experiments between 100 and $340{ }^{\circ} \mathrm{C}$ with a triangular temperature profile and a cycle period of $120 \mathrm{~s}$ with corresponding isothermal LCF tests at the minimum and maximum temperatures and at the same strain amplitude $(0.5 \%)$ and rate $\left(1.67 \cdot 10^{-2} \% / \mathrm{s}\right)$ in de-oxygenated high-purity high-temperature water (mean values of three tests under each condition). 
A significant environmental reduction of fatigue live was already observed at $100{ }^{\circ} \mathrm{C}$ and thus well below the temperature threshold of $150{ }^{\circ} \mathrm{C}$ in the NUREG/CR-6909 approach of the US NRC Regulatory Guide $1.207^{7}$. Above this temperature, the environmental reduction of fatigue life was increasing with increasing temperature (Figure 7) in contrast to air, where temperature usually only has a moderate effect between 100 and $340^{\circ} \mathrm{C}$. At $340{ }^{\circ} \mathrm{C}$, a reduction of fatigue live by a factor of almost 10 was observed with respect to air at this strain rate, which is only slightly below the strain rate threshold for environmental effects of $0.1 \% / \mathrm{s}$.

The TMF life was between that of the isothermal LCF tests at minimum and maximum temperature. The OP TMF life was 50 to $80 \%$ higher than in IP TMF tests. This is not unexpected based on the temperature effects, because the applied strains above the strain threshold $\varepsilon_{\text {th }}$ for environmental effects ( $\sim 0.125 \%$ ) occur at the high temperatures in IP TMF tests, whereas they occur at low temperatures for OP TMF experiments.

The evolution of the maximum and minimum stress over the whole fatigue live for the isothermal LCF tests at 100, 220 and $340{ }^{\circ} \mathrm{C}$ in high-temperature water and at $340{ }^{\circ} \mathrm{C}$ in air are shown in Figure 7. The significant decrease of fatigue life with increasing temperature in hightemperature water and the strong environmental reduction of the life at $340{ }^{\circ} \mathrm{C}$ are evident. The cyclic plastic behavior in air and high-temperature water was very similar, with an initial hardening followed by a softening phase. A secondary hardening phase is observed in air at the high temperature of $340{ }^{\circ} \mathrm{C}$, which increases with decreasing strain amplitude. Because of the significant environmental reduction of fatigue live at $340^{\circ} \mathrm{C}$, crack initiation occurred during the softening phase and the secondary hardening could not be seen at this strain amplitude. In Figure 8, the evolution of the maximum and minimum stress in the IP and OP TMF and isothermal LCF tests in de-oxygenated high-temperature water are compared. At this large strain amplitude, initial hardening and subsequent softening are observed only. As in the TMF tests in air, OP and IP TMF result in a slightly positive tensile and negative compressive mean 
stress, respectively, but in contrast to air, IP TMF lives are significantly shorter in hightemperature water for the previously mentioned reasons.

Figure 9a shows two examples of multiple isothermal LCF crack initiation and propagation at the inner wall of tubular specimens from tests at $220^{\circ} \mathrm{C}$. The axially cut specimen on the left side contains a large technical crack at the end of the gauge length. The technical CF crack within the gauge length of the specimen on the right side propagated through the complete wall thickness and resulted in a small leak. The cracks were always perpendicular to the stress axis and always initiated on the inner, water-touched surface. Figure 9b shows the fracture surface of a specimen from an IP TMF test without leak at the end of fatigue life broken apart by post-test fatigue in air. Several semi-elliptical cracks originating from the inner surface are clearly recognized. The deepest crack roughly reached half of the wall thickness at the $5 \%$ stress drop crack initiation criteria.

\section{TMF and isothermal LCF lives in BWR/HWC environment}

In a second test matrix, the TMF and isothermal LCF behavior was characterized under BWR/HWC conditions at a DH of $150 \mathrm{ppb}$ in the temperature range between 100 and $288{ }^{\circ} \mathrm{C}$. The TMF tests were performed at a constant mechanical strain rate $\Delta \varepsilon_{\text {mech }} / \Delta \mathrm{t}$ of $0.01 \% / \mathrm{s}$ for strain amplitudes $\Delta \varepsilon_{\text {mech }} / 2$ in the range from 0.25 to $0.5 \%$. Isothermal LCF experiments were conducted at 288 and $150{ }^{\circ} \mathrm{C}$ with mechanical strain rates of 0.1 and $0.01 \% / \mathrm{s}$ in the strain amplitude range from 0.15 to $0.5 \%$.

Figures 10 to 12 show the evolution of the stress response with the cycle number for the IP and OP TMF and isothermal LCF tests in BWR/HWC environment. The general cyclic plastic behavior in TMF and LCF tests was very similar. At strain amplitudes $\geq 0.3 \%$ initial cyclic hardening until to a maximum around 100 cycles (50 cycles at $\mathrm{LCF}$ at $150{ }^{\circ} \mathrm{C}$ ) was followed by subsequent cyclic softening until crack initiation. The amplitude of initial 
hardening thereby increased with increasing strain amplitude and increasing temperature. At strain amplitudes $<0.3 \%$ in TMF and isothermal LCF tests at $288{ }^{\circ} \mathrm{C}$, the cyclic softening was followed by secondary hardening until crack initiation, which is attributed to dynamic strain ageing. The secondary hardening thereby seemed to increase with decreasing strain amplitude (and, possibly, decreasing strain rate). Such a secondary hardening was not observed at $150{ }^{\circ} \mathrm{C}$ in isothermal LCF tests. Furthermore, OP and IP TMF result in a slightly positive tensile and negative compressive mean stress, respectively.

As in air the TMF and LCF lives in BWR/HWC environment decrease with increasing strain amplitude (Figure 12a). Above a strain amplitude of $0.2 \%$, the environmental reduction of fatigue life with respect to air under otherwise identical conditions seems to be constant and independent on strain amplitude (Figures 13 and 14). Below $0.2 \%$, it is expected that environmental effects decrease if the strain amplitude is approaching the strain threshold $\varepsilon_{\text {th }}$ for environmental effects of $\sim 0.125 \%$ (Figure 5).

The variation of strain rate and number of tested specimen was too small to derive clear conclusion with regard to strain rate effects (Figure 12b). According to NUREG/CR-6909 ${ }^{4}$, a reduction of strain rate from 0.1 to $0.01 \% / \mathrm{s}$ results in a reduction of the fatigue life by a factor 1.7, which is within the typical specimen to specimen variation from the same heat at large strain amplitudes. At small strain amplitudes close to the environmental threshold strain and fatigue endurance limit in the transition region to HCF, the specimen to specimen variation can easily reach a factor of 10 or more. A sufficiently large number of specimens has thus to be tested here to derive statistically significant conclusions. The reduction of the mechanical strain rate from 0.1 to $0.01 \% / s$ resulted in a slight reduction of isothermal LCF life at $288{ }^{\circ} \mathrm{C}$ at strain amplitudes $\geq 0.3 \%$ (Figure $12 \mathrm{c}$ ). At the strain amplitude of $0.2 \%$, the LCF life at $0.01 \% / \mathrm{s}$ was slightly longer than at $0.1 \% / \mathrm{s}$. This might be related to the increasing secondary hardening by dynamic strain ageing (negative strain rate sensitivity) at the smaller strain rate at $288{ }^{\circ} \mathrm{C}$, which 
might fully compensate the normal strain rate effect, but, again, further testing is necessary to confirm or disprove this speculation.

As in de-oxygenated high-temperature water (Figure 7), a significant reduction of isothermal LCF life was observed by increasing the temperature from 150 to $288{ }^{\circ} \mathrm{C}$ (Figure 12c) at large strain amplitudes $\geq 0.3 \%$. At the small strain amplitude the LCF life was comparable, which again might be related to the secondary hardening at $288{ }^{\circ} \mathrm{C}$, which is absent at $150{ }^{\circ} \mathrm{C}$ and may completely offset the usual temperature effects. Unusual temperature effects on physical fatigue initiation from sharp notches were also observed at small notch strain amplitudes, e.g., in Figure 25 of ${ }^{1}$ and in ${ }^{16,17}$.

Similar to de-oxygenated high-temperature water and in contrast to air, the OP TMF life is significantly longer (a factor of 3.3. to 4.5 for the applied conditions) than that in IP TMF experiments in BWR/HWC environment. The shorter IP TMF life can be explained based on the temperature effects discussed in the previous paragraph, because the applied strains above the threshold strain for environmental effects ( $0.125 \%)$ occur at the high temperatures in IP TMF tests, whereas they occur at low temperatures for OP TMF experiments. A comparison of the TMF tests in de-oxygenated high-temperature water and hydrogenated BWR/HWC environment shows that environmental reduction in OP TMF is similar in both environments and a factor 2 higher in IP TMF experiments under hydrogenated conditions, which would suggest a stronger effect of hydrogen under tensile stress at higher temperatures. Since the effect is still within the typical specimen to specimen variation at this strain amplitude and strain rates and temperature intervals were also slightly different, further experiments are necessary to confirm this hypothesis.

In Figure 13 the isothermal LCF lives in BWR/HWC environment at $288^{\circ} \mathrm{C}$ and at a strain rate of $0.1 \% / \mathrm{s}$ are compared with the environmental correction factor Fen predictions according to NUREG/CR-6909. For the larger strain amplitudes from 0.2 to $0.5 \%$ the LCF life 
of this specific heat is slightly shorter (a factor of $\sim 2$ ) than predicted, but still within the typical heat to heat and specimen to specimen variation. It also has to be kept in mind that the NUREG Fen approach is based on a regression analysis of a large data set of different stainless steel heats in simulated PWR primary environment or in de-oxygenated high-temperature water, which did not involve tests in this DH range. The surprisingly high life at $0.15 \%$ might be related to secondary hardening and dynamic strain ageing again.

The IP and OP TMF and isothermal LCF lives at $288{ }^{\circ} \mathrm{C}$ and a strain rate of $0.01 \% / \mathrm{s}$ in HWC environment are compared to the corresponding life times at $340{ }^{\circ} \mathrm{C}$ in air and to the ASME III and NUREG/CR-6909 air mean curves (Figure 14). Furthermore, the life predictions according to NUREG/CR-6909 at 288 and $100{ }^{\circ} \mathrm{C}$ and for different mean temperatures for IP and OP TMF, which can be calculated from the maximum and minimum temperature of the thermal cycle (288 and $100{ }^{\circ} \mathrm{C}$ ), the temperature threshold for environmental effects in NUREG/CR-6909 of $150^{\circ} \mathrm{C}$ and of the temperature, where the strain exceeds the strain threshold of $0.125 \%$ for environmental effects $\left(218^{\circ} \mathrm{C}\right.$ for IP TMF and $169{ }^{\circ} \mathrm{C}$ for OP TMF), are shown (Figure 14). Whereas the OP TMF lives fairly well agree with the NUREG predictions with the adequate mean temperature of 160 or $135^{\circ} \mathrm{C}$, the IP TMF were roughly a factor of 2 shorter than the corresponding NUREG/CR-6909 predictions with a mean temperature of $253{ }^{\circ} \mathrm{C}$. This difference is still regarded as acceptable, since it corresponds to the typical heat to heat and specimen to specimen variation.

Metallo- and fractographical post-test evaluations

Selected specimens from the tests presented above were opened by axial cutting or posttest fatigue in air (Figure 9b) for metallo- and fractographical post-test evaluations. These investigations were just started very recently and only some preliminary fractographical results 
can thus be shown in this paper.

The corrosion fatigue crack flank surfaces were investigated under the stereo-microscope at low magnification (see, e.g., Figure 9b) and then characterized by scanning electron microscopy in more detail.

The corrosion fatigue cracks were always straight and normal to the stress axis in deoxygenated and hydrogenated high-temperature water. The corrosion fatigue cracks appear to grow predominantly as Mode I tensile cracks normal to the stress axis, and small shear cracks (Mode II) near to the surface were not observed so far.

The fatigue fracture morphology of crack growth into the material in air and deoxygenated or hydrogenated high-temperature water did not differ significantly, which suggests the same underlying crack growth process. Well-defined fatigue striations were clearly visible on most parts of the fatigue crack flanks in air and high-temperature water. Two examples (from IP TMF tests in air and high-temperature water) are shown in Figure 15. The width or spacing of the striations was significantly larger in high-temperature water under otherwise similar conditions and correlated fairly well with the macroscopic crack growth and its environmental acceleration under the given conditions. The presence of well-defined striations suggests that mechanical factors are still dominant over dissolution effects (e.g., slip dissolution mechanism) in the cracking process.

Close to the inner wall, where the cracks initiated, the striations were hardly visible or the surface was even striation-free. This might be related to the longer oxidation period of the surface closer to the crack initiation site, to crack closure effects or a different mechanism for physical crack initiation and subsequent short crack growth. The striation width becomes larger with increasing strain amplitudes and with increasing distance from the inner wall, where the cracks initiated, and thus with increasing local stress intensity amplitudes. 
Since the total number of fatigue cycles to technical initiation $\mathrm{N}_{\mathrm{f} 5}$ during each test is known and assuming that each fatigue cycle produces one striation, the number of cycles to physical crack initiation $\mathrm{N}_{\mathrm{i}}$ can be estimated by counting the fatigue striations on a crack flank. The results of such a very preliminary evaluation are summarized in Figure 16. The number of cycles to physical crack initiation $\mathrm{N}_{\mathrm{i}}$ in percent of the total fatigue life time $\mathrm{N}_{\mathrm{f} 5}$ increases with decreasing strain amplitude. At small strain amplitudes $\leq 0.25 \%$, the physical initiation life dominates the total lifetime, whereas at large strain amplitudes $\geq 0.5 \%$ it is mainly governed by the crack growth. Under BWR/HWC conditions the cycles to physical and technical crack initiation in case of IP TMF is smaller than for OP TMF. These observations are in good agreement with the previously discussed test results.

In the future, a careful comparison of the striation-based crack growth rate $\mathrm{da} / \mathrm{dN}$ as function of crack depth for tests in air and high-temperature water under otherwise similar conditions should help to separate the effect of environment on physical initiation and on the subsequent short and long crack growth as a function of applied strain amplitude. In tests with sharply notched fracture mechanics specimen at PSI ${ }^{1}$, the effect of the environment on the physical crack initiation was significantly higher than on the subsequent short crack growth in test in hydrogenated high-temperature water. For the latter, the environmental acceleration was similar as in tests with long cracks in pre-cracked fracture mechanics specimens. Further investigations by metallography, SEM/EBSD and TEM might help to identify the mechanism of environmental effects.

\section{SUMMARY AND CONCLUSIONS}

Two unique facilities for isothermal LCF and IP or OP TMF testing of tubular specimens under BWR and PWR coolant conditions were set up and successfully tested. With the installed 
system, IP and OP TMF experiments between 100 and $340{ }^{\circ} \mathrm{C}$ can be performed with a triangular temperature profile with a minimum cycle period of $120 \mathrm{~s}$ with minimal axial and through-wall temperature gradients, fulfilling the requirements of international standards for TMF experiments. The systems allow both strain- and stress-controlled fatigue experiments with very small strain amplitudes or complex stress/strain profiles with superimposed rather rapid temperature changes under flowing conditions, which are some of the major advantages with regard to autoclave tests. The first batch of tests revealed the following important preliminary conclusions:

Within a previous project ${ }^{10}$ it was shown that there is little effect of temperature on isothermal LCF and TMF life in air between 100 and $340{ }^{\circ} \mathrm{C}$ at strain amplitudes $\geq 0.3 \%$. The slightly shorter OP TMF life in air is related to the evolution of the slightly positive tensile mean stress.

In contrast to air and in agreement with observations from other corrosion fatigue experiments performed at PSI ${ }^{1,2}$, a strong effect of temperature on LCF and TMF lives was observed in de-oxygenated and hydrogenated (BWR/HWC) high-temperature water environment, where both lives decrease with increasing temperature above $100{ }^{\circ} \mathrm{C}$.

The TMF life is between that of the isothermal LCF tests at minimum and maximum temperature. The IP TMF life is shorter than that of OP TMF and close to the LCF life at maximum temperature. The OP TMF life is close to that of LCF at minimum temperature. The shorter IP TMF life is not unexpected based on the temperature effects, because the applied strains above the threshold strain for environmental effects $(\sim 0.125 \%)$ occur at the high temperatures in IP TMF tests, whereas they occur at low temperatures for OP TMF experiments.

In BWR/HWC environment, the LCF and TMF lives seem to be slightly shorter than predicted by the NUREG/CR-6909 approach of the US NRC Reg. Guide 1.207. Significant 
environmental effects were observed at $100{ }^{\circ} \mathrm{C}$, which is significantly below the temperature threshold of $150{ }^{\circ} \mathrm{C}$. Because of the increasing secondary hardening at high temperatures with decreasing strain amplitudes, opposite temperature effects and a different TMF behavior might occur at very small and thus more plant-relevant strain amplitudes in air and high-temperature water environment. More pronounced heat to heat variations are also expected under these conditions.

The macroscopic cyclic stress-strain response is very similar in high-temperature water and in air, which suggests that the underlying micro-plastic deformation processes are not fundamentally changed by the high-temperature water environment. This has to be verified by corresponding microscopic investigations.

The fatigue fracture morphology of crack growth into the material in air and deoxygenated or hydrogenated high-temperature water does not differ significantly, which suggests the same underlying crack growth process. Well-defined fatigue striations were clearly visible on most parts of the fatigue crack flanks in air and high-temperature water.

\section{ACKNOWLEDGEMENTS}

The authors would like to acknowledge the financial support from the Swiss Federal Nuclear Safety Inspectorate (ENSI). Many thanks are addressed to B. Baumgartner, L. Nue and

R. Schwenold (all PSI), for their excellent technical support and to M. Schachermayer (Montanuniversität Leoben, Austria) for the fractographical evaluation. 


\section{REFERENCES}

1. H.P. Seifert, S. Ritter, and H.J. Leber, "Corrosion Fatigue Initiation and Short Crack Growth Behaviour of Austenitic Stainless Steels under Light Water Reactor Conditions", Corrosion Science, 2012, 59, pp. 20-34.

2. H.P. Seifert, S. Ritter, and H.J. Leber, "Corrosion Fatigue Crack Growth Behaviour of Austenitic Stainless Steels under Light Water Reactor Conditions", Corrosion Science, 2012, 55, pp. 61-75.

3. H.P. Seifert, S. Ritter, "Environmentally-assisted cracking in austenitic light water reactor structural materials - final report of the KORA-I project”, PSI report, No. 09-03, ISSN 1019-0643, Paul Scherrer Institute, Villigen PSI, Switzerland, 2009.

4. O.K. Chopra, W.J. Shack, "Effect of LWR coolant environments on the fatigue life of reactor materials”, NUREG/CR-6909, US NRC, Washington DC, USA, February 2007, available from: http://www.nrc.gov/ (viewed on September 1, 2011).

5. O. K. Chopra, W. J. Shack, "A review of the effects of coolant environments on the fatigue life of LWR structural materials”, Journal of Pressure Vessel Technology, 2009, 131, pp. 021409-4-021409-21.

6. D.R. Tice, D. Green, A. Toft, "Environmentally assisted fatigue gap analysis and roadmap for future research: Gap analysis report”, EPRI Report, No. 1023012, EPRI, Palo Alto, California, USA, December 2011, available from: http://my.epri.com/ (viewed on January 31, 2012).

7. US NRC Regulatory Guide 1.207, “Guidelines for evaluating fatigue analyses incorporating the life reduction of metal components due to the effect of the light-water reactor environment for new reactors”, US NRC, Washington DC, USA, March 2007, available from: http://www.nrc.gov/ (viewed on September 1, 2012).

8. M. Higuchi, "Comparison of environmental fatigue evaluation methods in LWR water", in: ASME 2008 Pressure Vessel and Piping Conference (PVP 2008), Paper No. PVP200861087, ASME, Chicago, Illinois, USA, July 27-31, 2008.

9. W.A. Van Der Sluys, "PVRC's position on environmental effects on fatigue life in LWR applications”, Welding Research Council Bulletin, 2003, 487, Welding Research Council, Inc., New York.

10. M. Ramesh, “Thermomechanical fatigue behavior of austenitic stainless tube and pipe steels 
under light water reactor relevant temperature conditions and associated microstructural evolution”, DISS. ETH Nr. 19137, ETH Zürich, Zürich, Switzerland, June 2010.

11. M. Ramesh, H.J. Leber, K. G.F. Janssens, M. Diener, R. Spolenak, “Thermomechanical and isothermal fatigue behavior of 347 and 316L austenitic stainless tube and pipe steels”, Int. Journal of Fatigue, 2011, 33(5), pp. 683-691.

12. M. Ramesh, H.J. Leber, M. Diener, R. Spolenak, "Conducting thermomechanical fatigue test in air at light water reactor relevant temperature intervals", Journal of Nuclear Materials, 2011, 415(1), pp. 23-30.

13. P. Hähner, E. Affeldt, T. Beck, H. Klingelhöffer, M. Loveday, C. Rinaldi, "Validated Codeof-Practice for Strain-Controlled Thermo-Mechanical Fatigue Testing”, EUR 22281 EN, ISBN 92-79-02216-4, European Communities, Luxembourg, 2006.

14. ASTM E2368-04, "Standard Practice for Strain Controlled Thermomechanical Fatigue Testing”, ASTM Int., West Conshohoken, 2005.

15. ISO/DIS 12111, "Strain Controlled Thermomechanical Fatigue Testing Method”, Draft Int. Standard, Int. Standard Organisation, Geneva, 2008.

16. C. Amzallag, "Effect of PWR environment on the fatigue behaviour of a $304 \mathrm{~L}$ stainless steel”, in: Fontevraud 6 Conf. on Contributions of Materials Investigations to Improve Safety and Performance of LWRs, Paper No. A022-T05, Fontevraud, France, September 18-22, 2006.

17. H.D. Solomon, C. Amzallag, R.E. DeLair and A.J. Vallee, "Strain controlled fatigue of type 304L SS in air and PWR water", in: $3^{\text {rd }}$ Int. Conf. on Fatigue of Reactor Components, EPRI/OECD, Seville, Spain, October 3-6, 2004. 


\section{TABLES}

TABLE 1

Chemical composition of the investigated AISI 316L austenitic stainless steel pipe material (values in wt.-\%).

\begin{tabular}{cccccccccccc}
\hline $\mathrm{C}$ & $\mathrm{Si}$ & $\mathrm{Mn}$ & $\mathrm{P}$ & $\mathrm{S}$ & $\mathrm{Cr}$ & $\mathrm{Mo}$ & $\mathrm{Ni}$ & $\mathrm{Nb}$ & $\mathrm{N}$ & $\mathrm{Ti}$ & $\mathrm{Fe}$ \\
\hline 0.021 & 0.26 & 1.69 & 0.033 & 0.003 & 17.5 & 2.15 & 11.14 & 0.06 & 0.012 & 0.003 & Bal. \\
\hline
\end{tabular}

TABLE 2

Mechanical properties of the investigated AISI 316L austenitic stainless steel at room temperature in the as-received condition, obtained by tensile tests according to EN 10002-1.

\begin{tabular}{ccccc}
\hline $\begin{array}{c}\text { Yield strength } \\
\mathrm{R}_{\mathrm{p} 0.2}[\mathrm{MPa}]\end{array}$ & $\begin{array}{c}\text { Tensile } \\
\text { strength } \\
\mathrm{R}_{\mathrm{m}}[\mathrm{MPa}]\end{array}$ & $\begin{array}{c}\text { Elongation at } \\
\text { fracture } \\
\mathrm{A}[\%]\end{array}$ & $\begin{array}{c}\text { Reduction of area } \\
\mathrm{Z}[\%]\end{array}$ & $\begin{array}{c}\text { Young's modulus } \\
\mathrm{E}[\mathrm{GPa}]\end{array}$ \\
\hline $220 \pm 5$ & $523 \pm 1$ & $64 \pm 2$ & $83 \pm 1$ & $203 \pm 3$ \\
\hline
\end{tabular}




\section{FIGURES AND CAPTIONS}
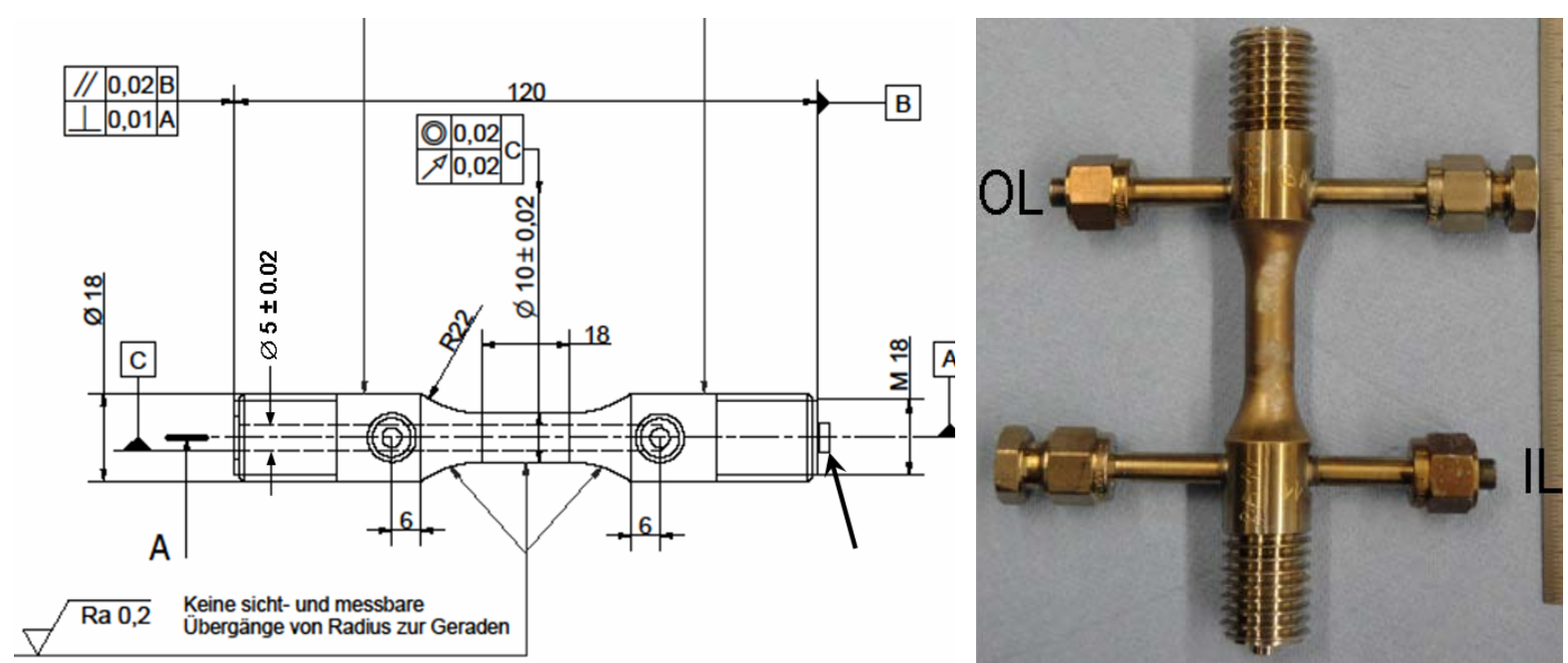

FIGURE 1. Tubular specimen for TMF and isothermal LCF tests; left: technical drawing (dimensions in $\mathrm{mm}$ ); right: tested specimen with inlet (IL), outlet (OL) and two dead end nozzles.

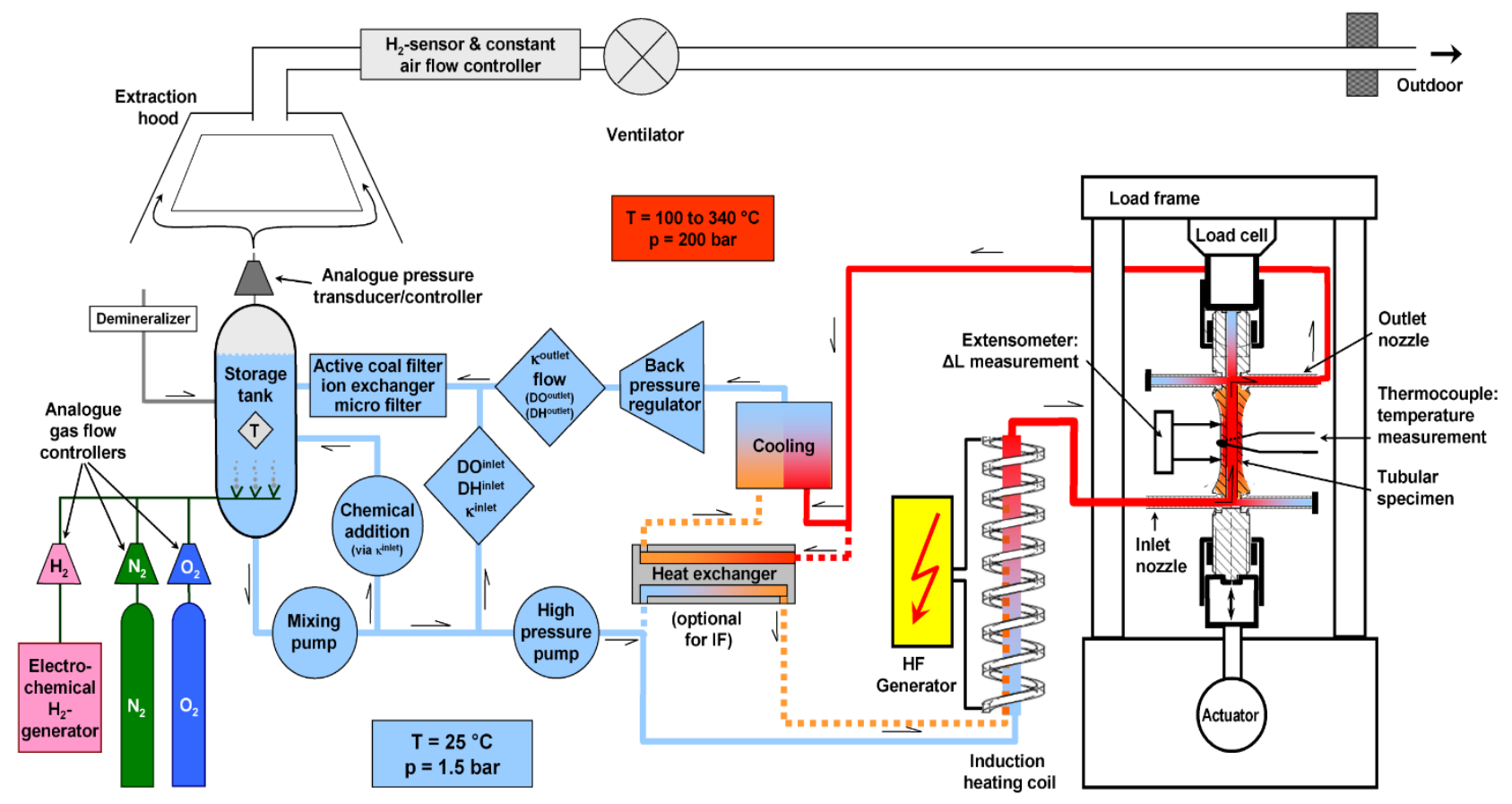

FIGURE 2. Schematic of the high-temperature water loop and TMF/LCF testing system. 

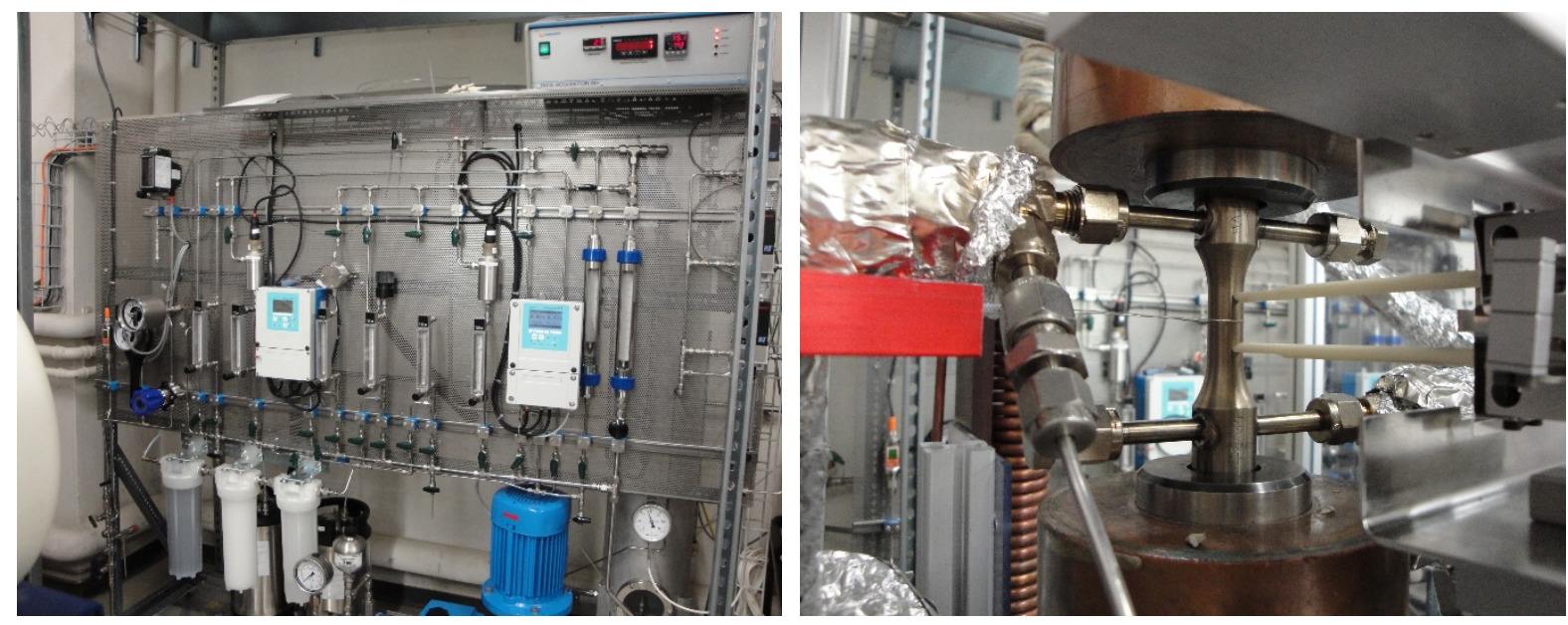

FIGURE 3. Left: overview of the high-temperature water loop; right: view of the specimen chamber with thermocouple and extensometer fixed on the specimen (LCF facility).

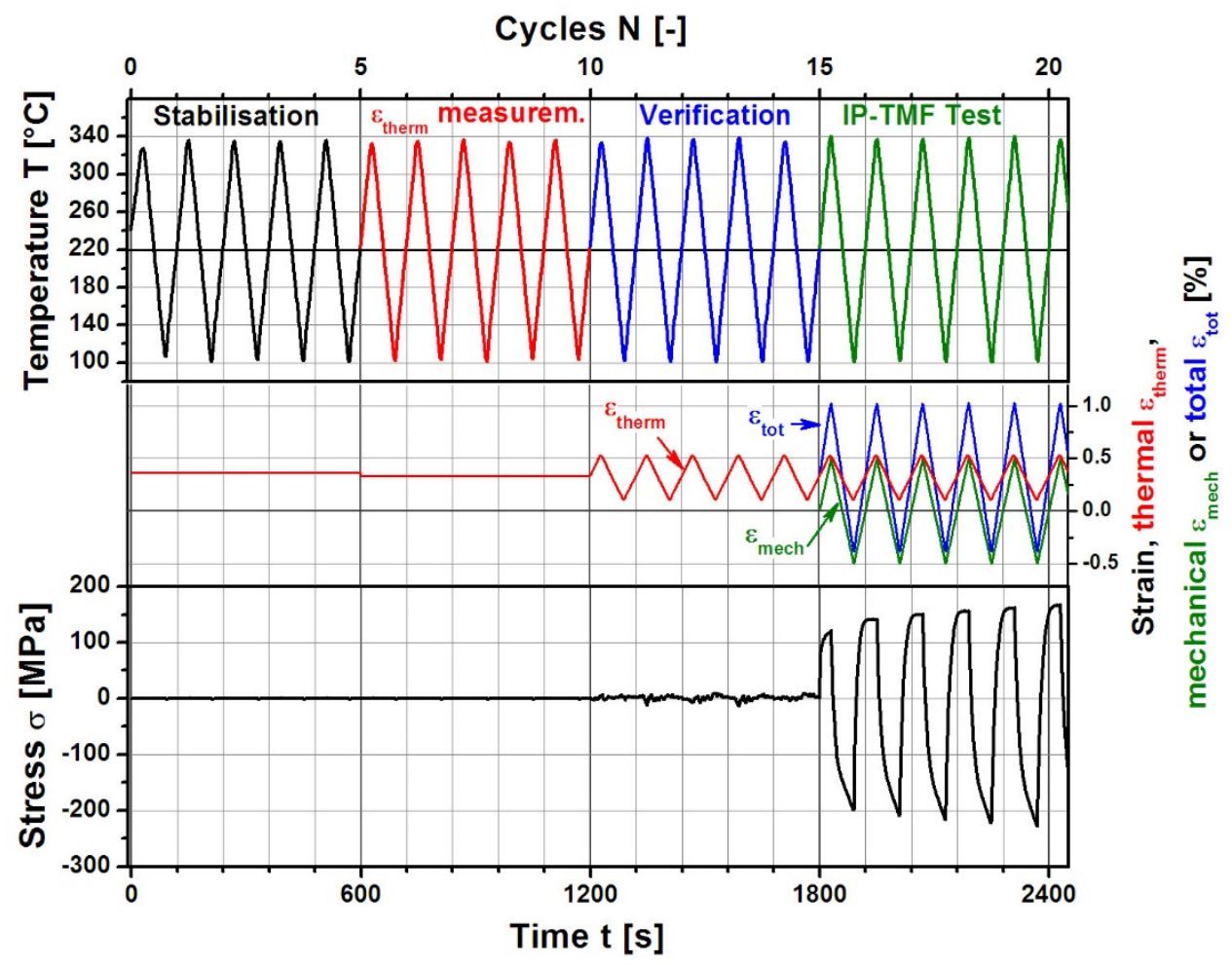

FIGURE 4. Preliminary and main test phases of TMF cycling in high-temperature water $\left(100{ }^{\circ} \mathrm{C} \leq T \leq 340^{\circ} \mathrm{C}\right.$ ) according to the "Code of Practice" 13 . 

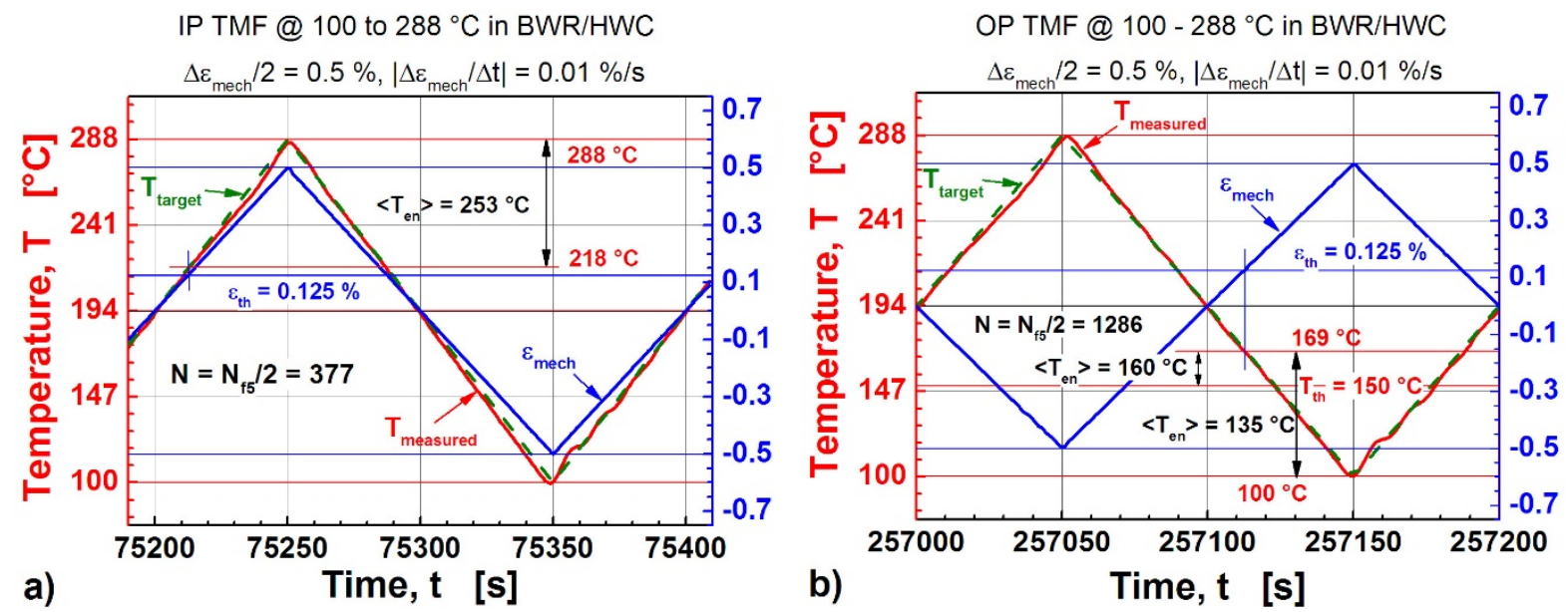

FIGURE 5. Examples of the course of temperature and mechanical strain during a cycle in an IP (a) and OP TMF (b) test with mean temperatures for TMF life prediction according to NUREG/CR-6909 3 .
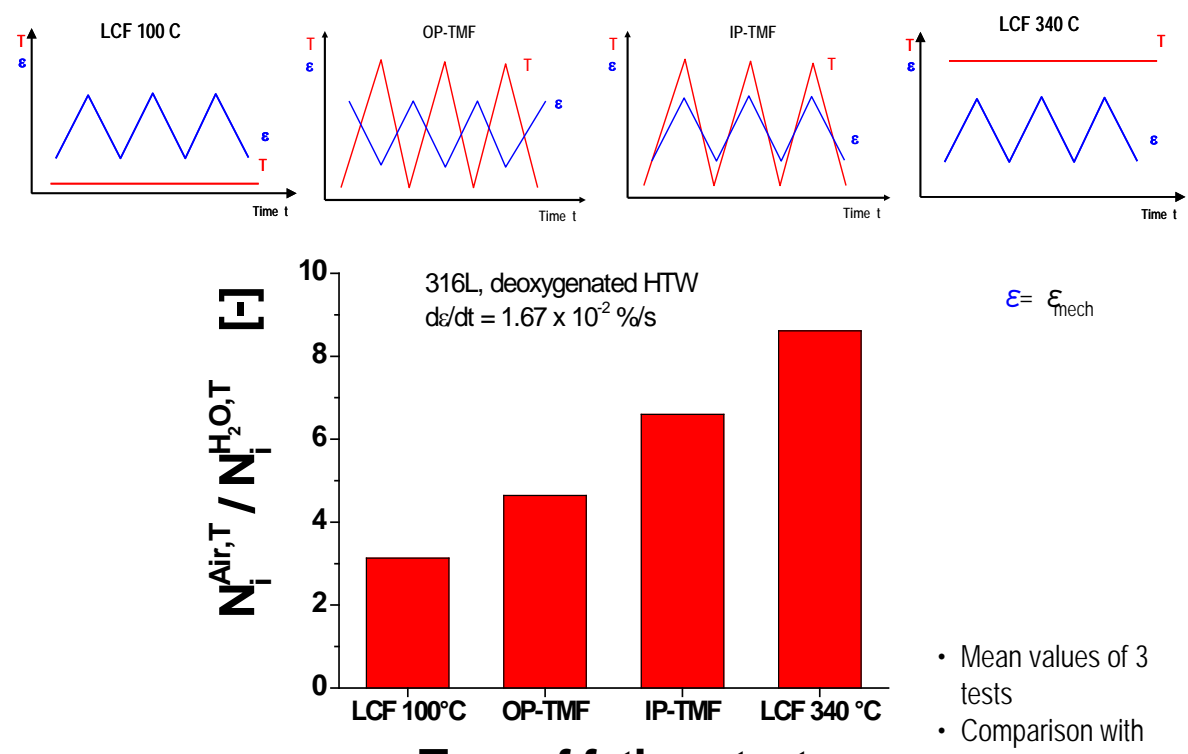

Type of fatigue test

- Mean values of 3 tests

- Comparison with real air tests

FIGURE 6. Fatigue life reduction in high-temperature water compared to air for four different types of fatigue tests. 
Isoth. LCF, triangular waveform, $\Delta \varepsilon / 2=0.5 \%, v=8.33 \cdot 10^{-3} \mathrm{~Hz}$,

$\left|\Delta \varepsilon_{\text {mech }} / \Delta \mathrm{t}\right|=0.0167 \% / \mathrm{s}$, de-oxygenated high-temperature water

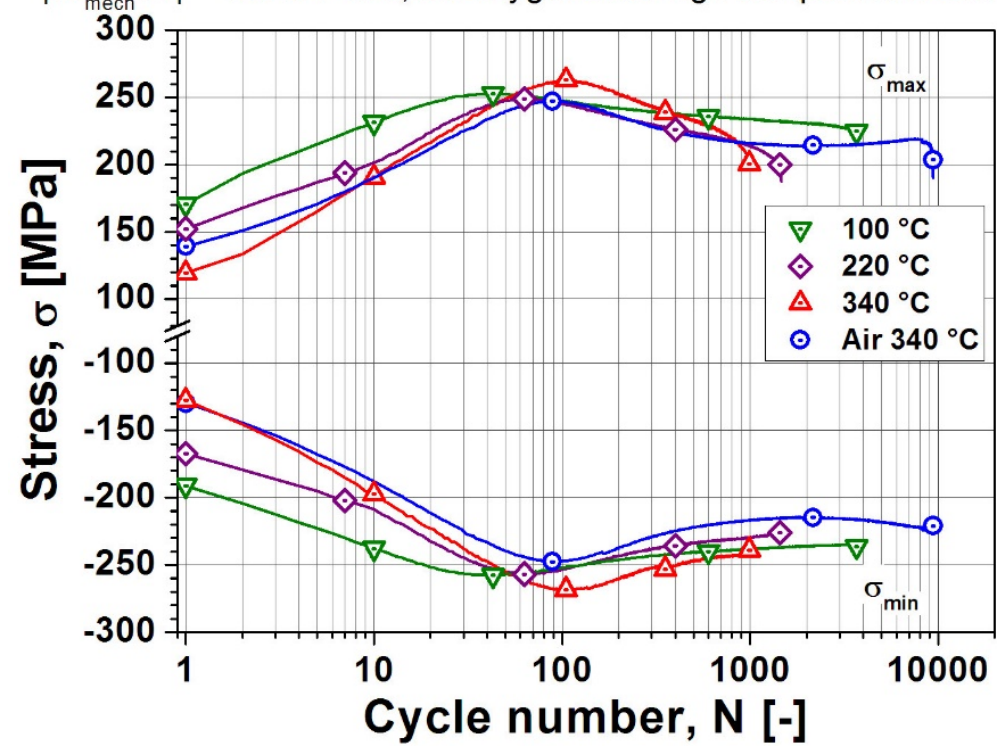

FIGURE 7. Stress response to isothermal LCF cycles in de-oxygenated hightemperature water at extreme and mean TMF temperatures in comparison to isothermal $L C F$ at $340^{\circ} \mathrm{C}$ in air.

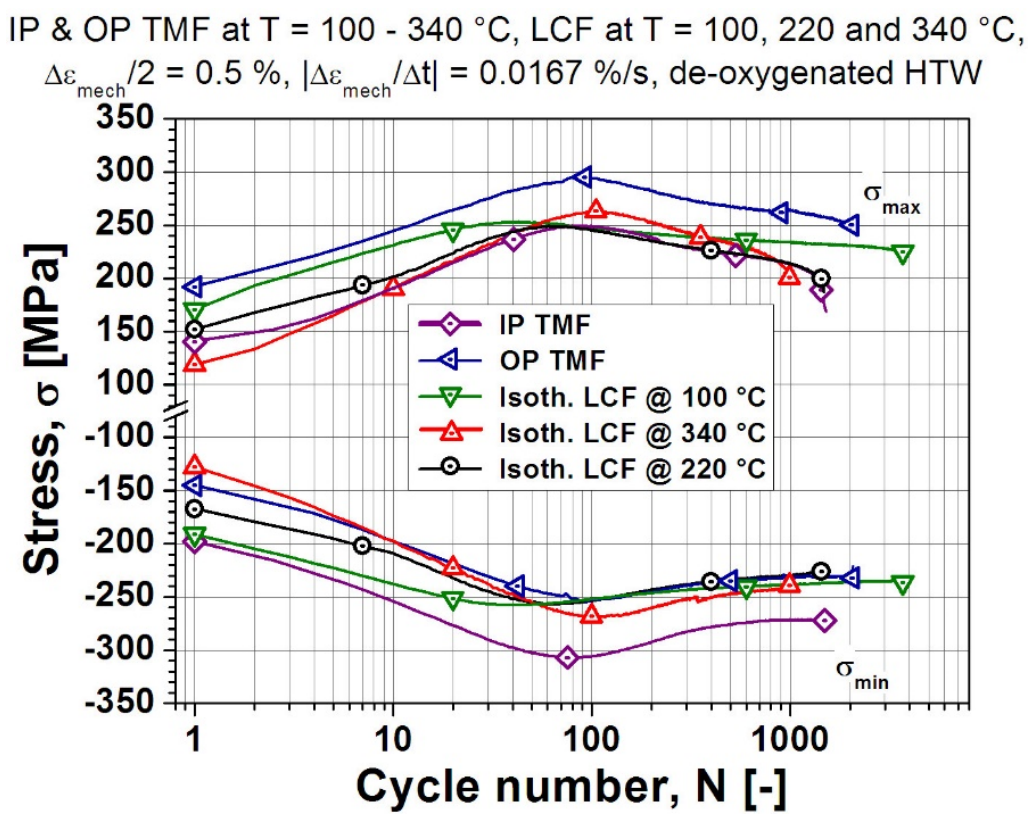

FIGURE 8. Stress response to fatigue cycles in de-oxygenated high-temperature water of IP and OP TMF, and of isothermal LCF at extreme and mean TMF interval temperatures. 


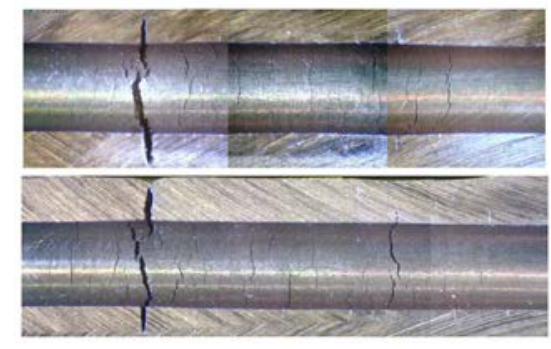

Technical CF crack at the end of the gauge length

a)

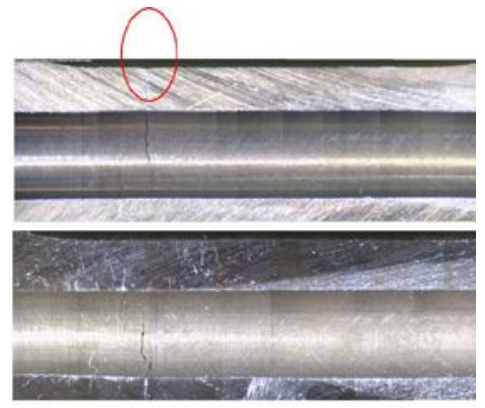

Technical CF crack with leak within the gauge length

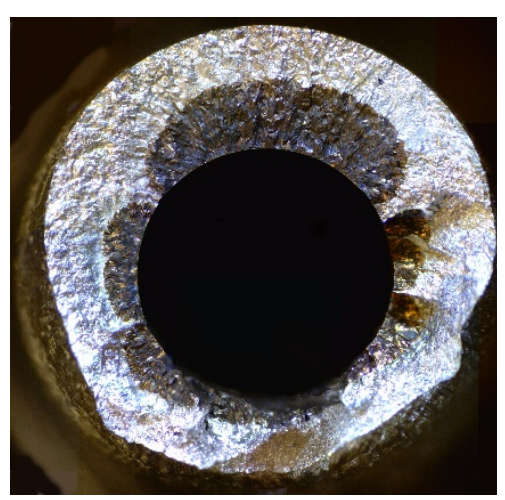

b)

FIGURE 9. a) Multiple crack initiation at the inner wall of axially cut tubular specimens.

b) Several semi-elliptical, technical CF cracks (dark) revealed after fracture by posttest fatigue in air.

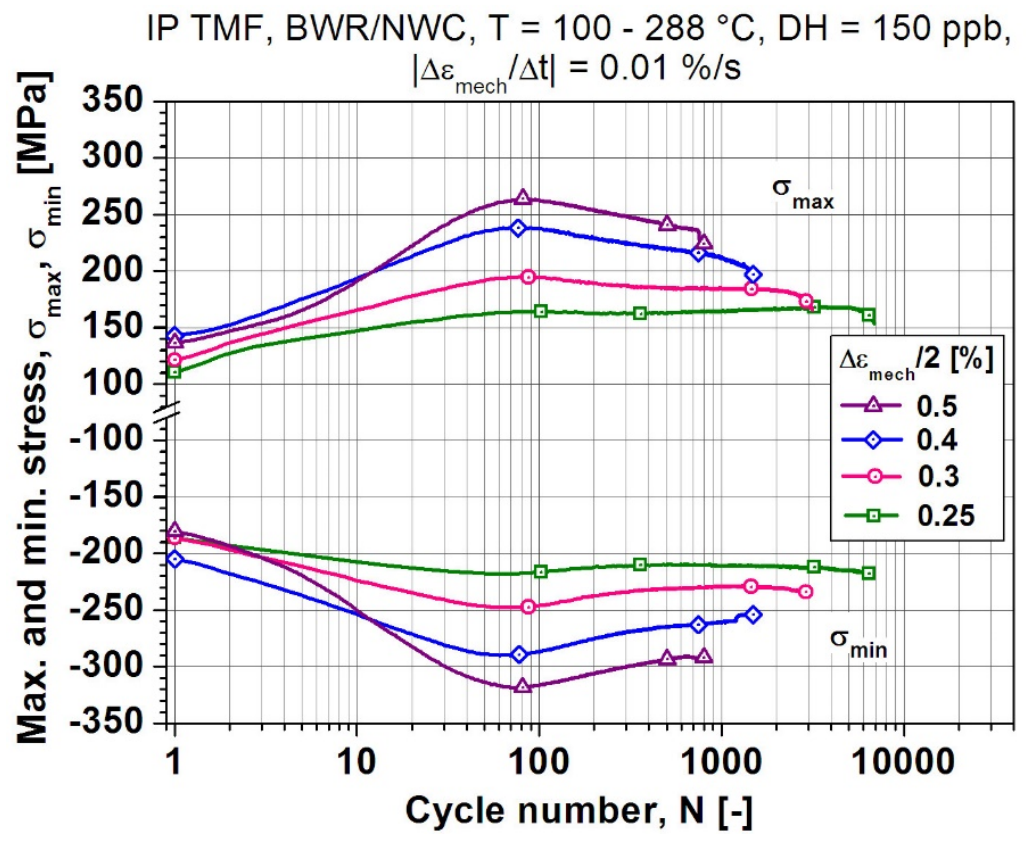

FIGURE 10. Maximum and minimum stress response vs. cycle number for IP TMF tests under BWR/HWC conditions for different strain amplitudes. 


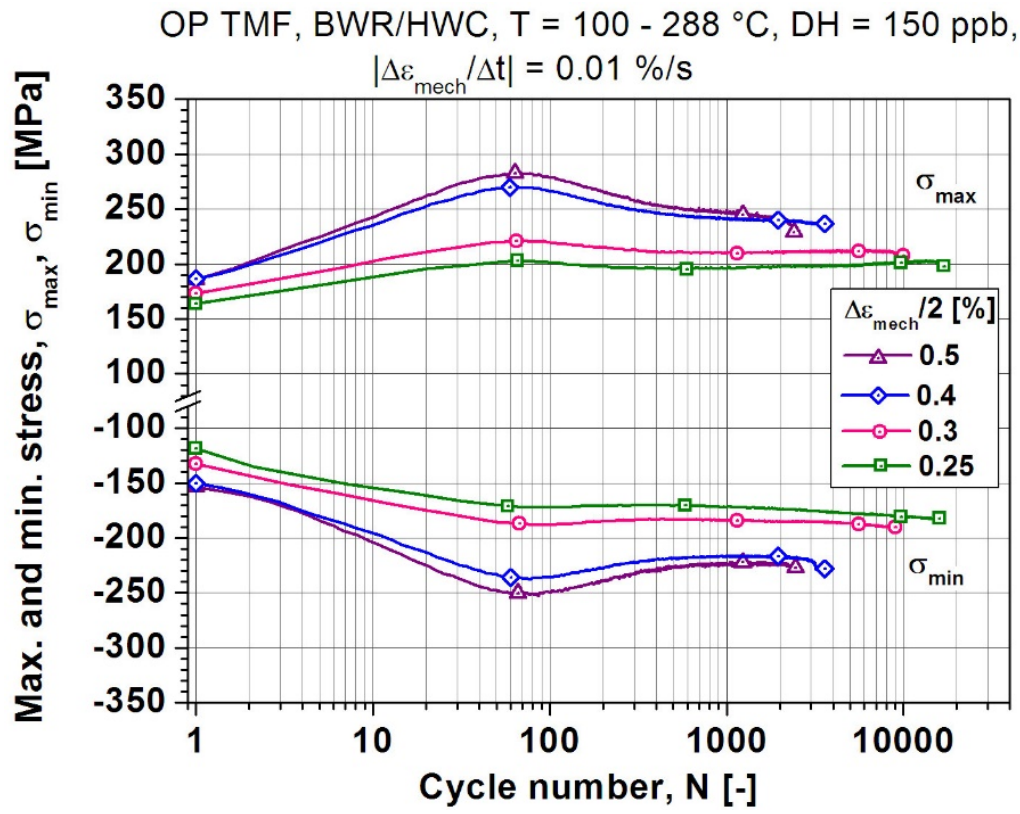

FIGURE 11. Maximum and minimum stress response vs. cycle number for OP TMF tests under BWR/HWC conditions for different strain amplitudes. 


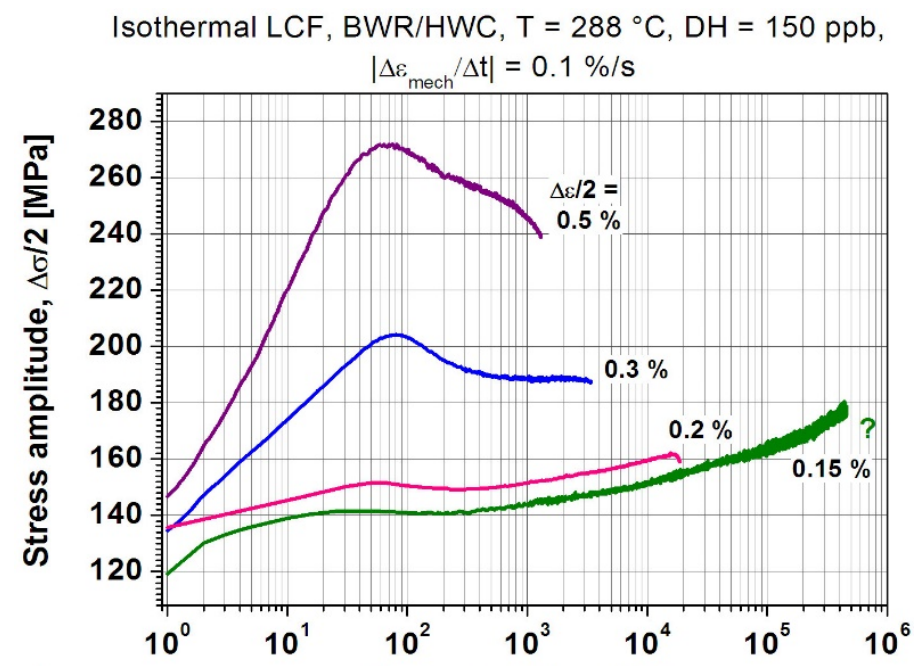

a)
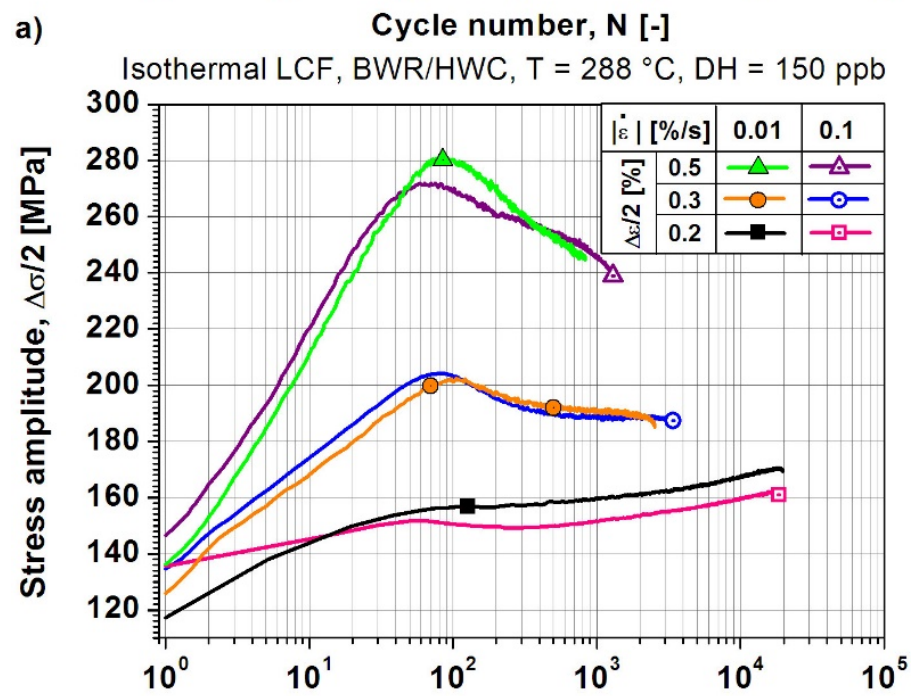

b)

Cycle number, $\mathrm{N}$ [-]

Isothermal LCF, BWR/HWC, DH = $150 \mathrm{ppb},|\Delta \varepsilon / \Delta \mathrm{t}|=0.01 \% / \mathrm{s}$

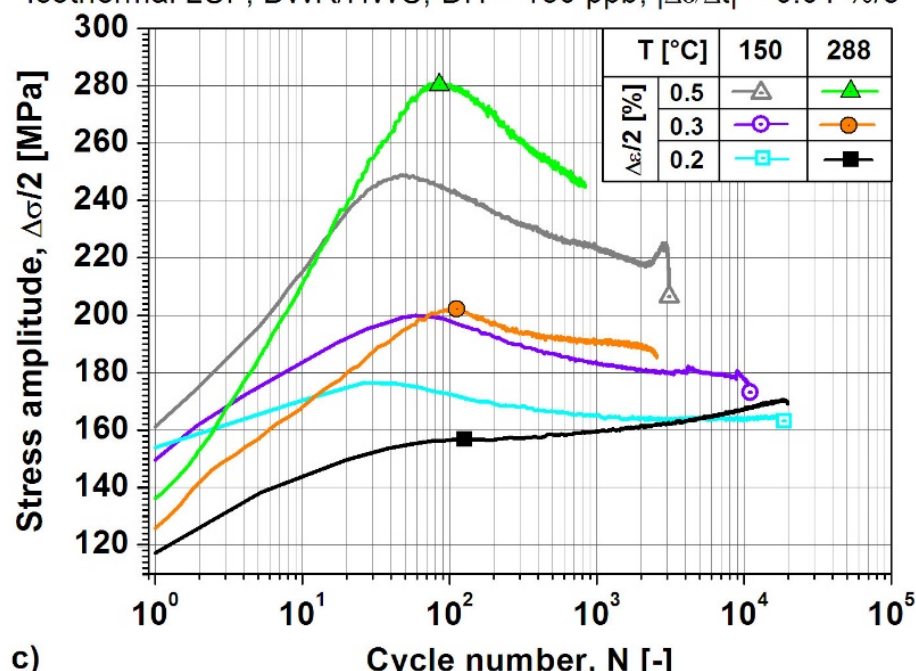

c)

Cycle number, $\mathrm{N}[-]$

FIGURE 12. Stress amplitude vs. fatigue cycles for isothermal LCF tests: a) $T=288$ $\left.{ }^{\circ} \mathrm{C}, D H=150 \mathrm{ppb},\left|\Delta \varepsilon_{\text {mech }} / \Delta t\right|=0.1 \% / \mathrm{s} ; b\right)$ effect of strain rate, $\left|\Delta \varepsilon_{\text {mech }} / \Delta t\right|=0.1$ and $0.01 \% / \mathrm{s} ; \mathrm{c}$ ) effect of temperature, $T=288$ and $150^{\circ} \mathrm{C}$. 
Isoth. LCF tests in HWC @ $288^{\circ} \mathrm{C},\left|\Delta \varepsilon_{\text {mech }} / \Delta \mathrm{t}\right|=0.1 \% / \mathrm{s}$

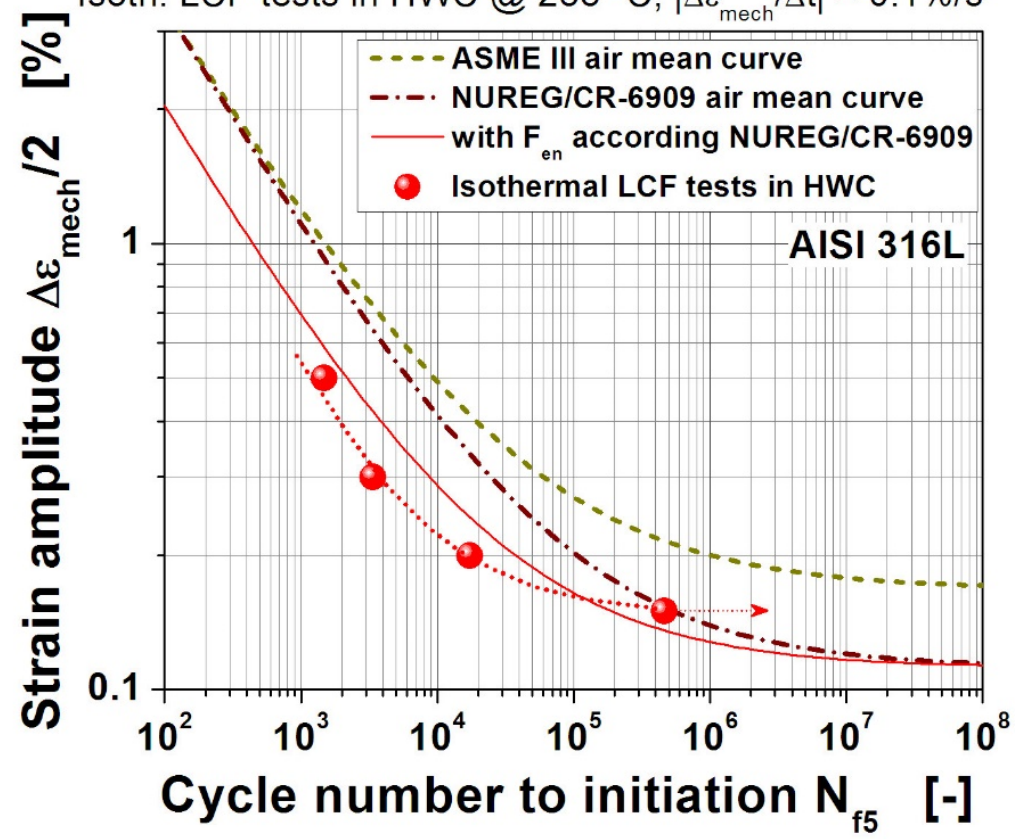

FIGURE 13. Comparison of isothermal fatigue life times in HWC with ASME III and NUREG/CR-6909 air mean curves and with $F_{\text {en }}$ predictions according to NUREG/CR69093.

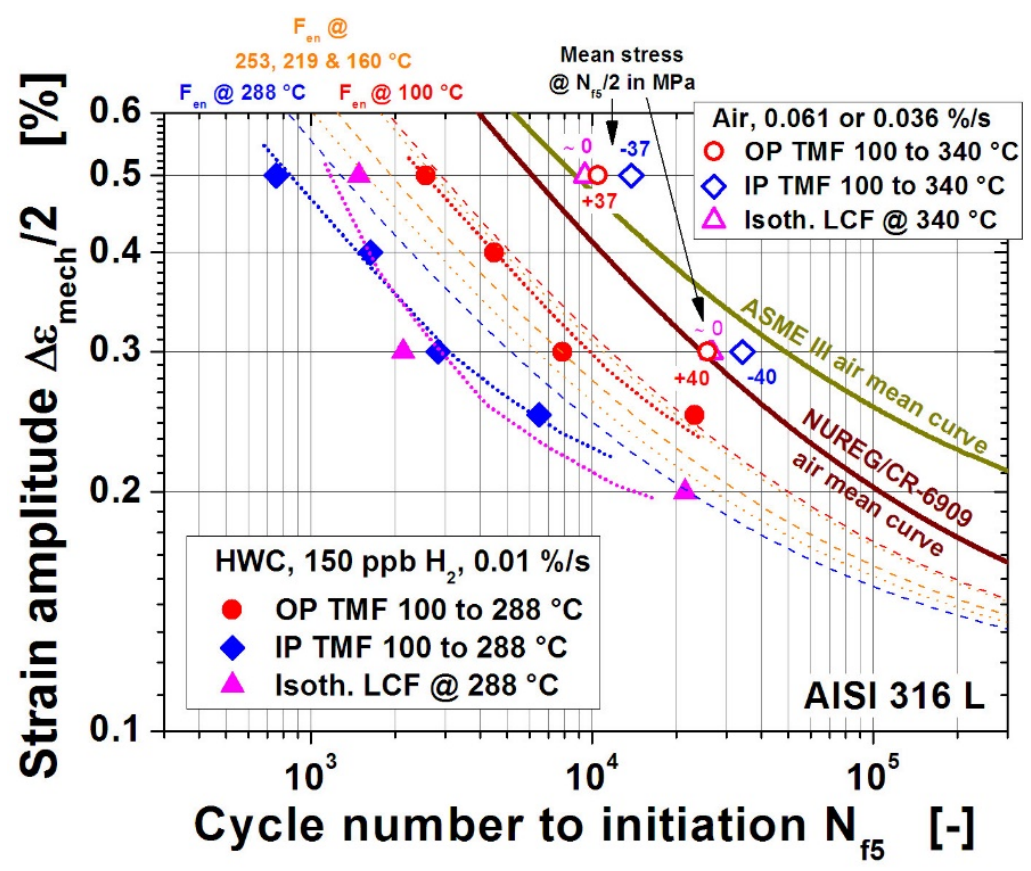

FIGURE 14. Comparison of fatigue life times of IP and OP TMF and LCF at $288^{\circ} \mathrm{C}$ in BWR/HWC to IP and OP TMF and LCF at $340{ }^{\circ} \mathrm{C}$ in air and to ASME III and NUREG/CR-6909 air mean curves ${ }^{3}$. 


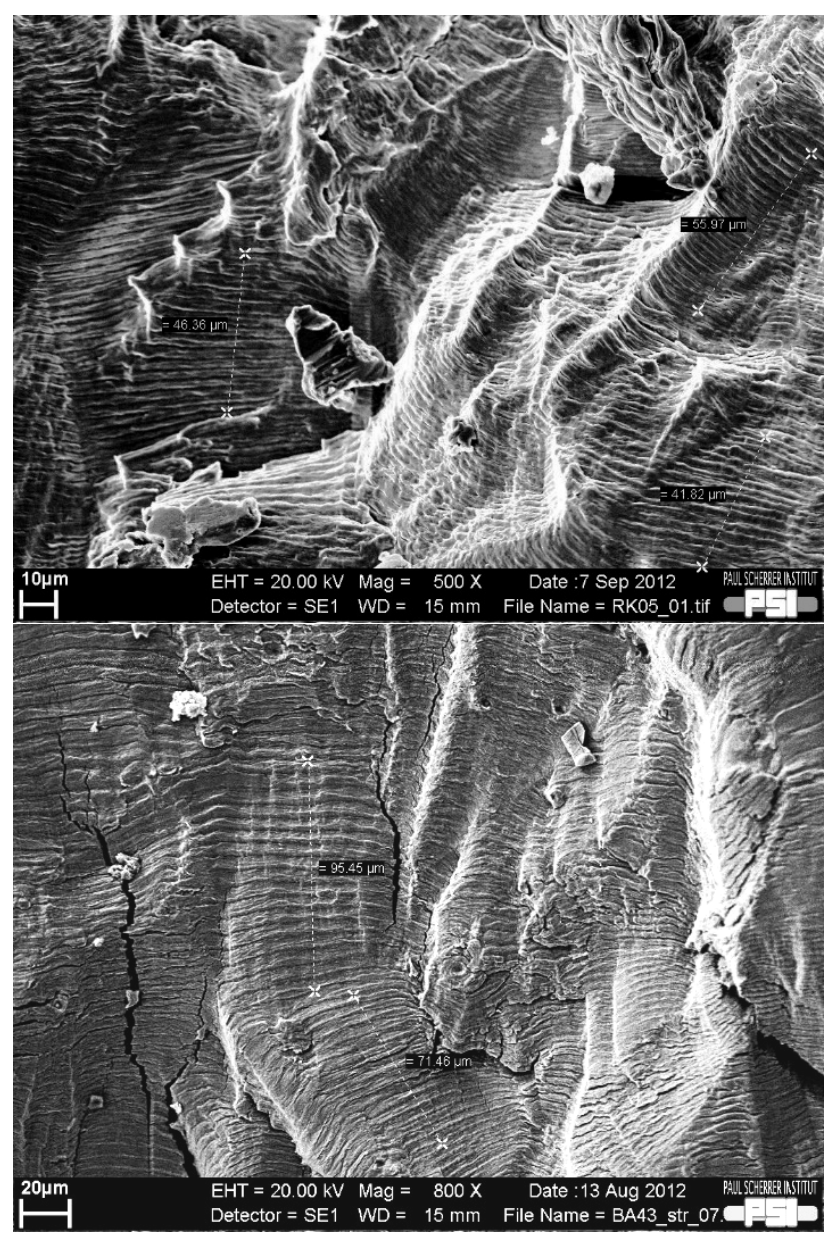

FIGURE 15. SEM micrographs of fatigue crack flank surfaces with striations form IP TMF tests with a mechanical strain amplitude of $0.5 \%$; left: in air, right: in hydrogenated high-temperature water. 


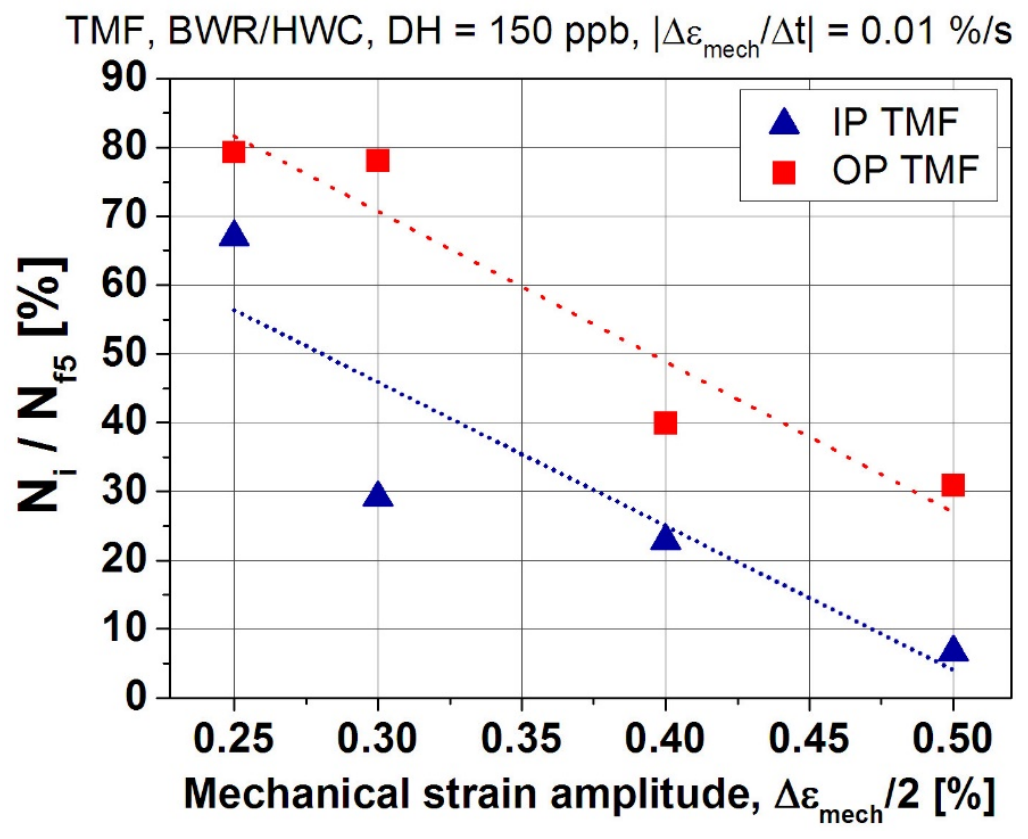

FIGURE 16. Estimated number of cycles to physical crack initiation $N_{i}$ in percent of the total fatigue life time $N_{f 5}$ for IP and OP TMF tests in hydrogenated high-temperature water with different mechanical strain amplitudes. 